\title{
Evidence and Significance of Self-pollination of Avocados in Florida
}

\author{
Thomas L. Davenport ${ }^{1}$, Petra Parnitzki, Sabine Fricke, and Melanie S. Hughes \\ University of Florida, Institute of Food and Agricultural Sciences, Tropical Research and Education \\ Center, 18905 SW 280 St., Homestead, FL 33031
}

Additional index words. Persea americana, flowering, fruit set, pollination

\begin{abstract}
Pollination was investigated in five avocado (Persea americana Mill.) cultivars during two seasons. In the first year, 'Simmonds' and 'Hardee' branches with inflorescences were covered with cheesecloth bags to prevent pollination by large flying insects during either or both the first (Stage I) and second (Stage II) floral openings. Adjacent, tagged branches were left open as controls. The proportion of pollinated Stage I flowers ranged from <1\% in 'Simmonds' to $9 \%$ in 'Hardee.' Pollination rates in Stage II ranged from 15\% in 'Simmonds' to nearly $69 \%$ in 'Hardee'. Pollination during Stage II was proportional to the number of white stigmas available during that stage. Stage II pollination rates for bagged flowers and open flowers were similar, even though large flying insects were barred from bagged flowers. In the second year, similar experiments on cultivars Simmonds, Tonnage, Tower 2 , and Choquette provided results consistent with those obtained the previous year. Virtually no pollination occurred in bagged Stage I flowers in all cultivars tested, and $\approx 1 \%$ of the open Stage I flowers were pollinated. Pollination of bagged and open Stage II flowers was generally the same within cultivars. The percent pollination of Stage II flowers ranged from a mean of $4.3 \%$ to $35 \%$, depending on cultivar. The results show that self-pollination during the Stage II floral opening is the primary means of pollination of commercial cultivars grown in Florida. Moreover, the presence of developing fruits on branches bagged during the flowering season demonstrated that fruit set can occur without pollination by large flying insects.
\end{abstract}

Flowering patterns of avocado (Persea americana Mill.) have been documented in great detail (Davenport, 1986; Nirody, 1922; Stout, 1923). Briefly, flowers are borne on lateral cymose inflorescences (Finazzo et al., 1993). They are perfect, exhibiting synchronously dichogamous behavior that occurs in two floral openings. In the first opening (Stage 1), which lasts 3 to $4 \mathrm{~h}$, the flowers are functionally female. No pollen is released and stigmas appear white and are receptive to pollination. The second opening (Stage II) of the same flowers, which also lasts 3 to $4 \mathrm{~h}$, occurs the following day. This opening is functionally male because pollen is released and stigmas desiccate (Nirody, 1922). Cultivars are classified according to the timing of the floral openings. Type A shows Stage I flowers in the morning and Stage II flowers in the afternoon of the following day while Type B shows Stage I flowers opening in the afternoon and Stage II flowers opening the following morning (Stout, 1923). Pollination is thought to occur only during Stage I and that large flying insects, such as honeybees (Apis mellifera), cross-pollinate by transferring pollen from nearby complementary cultivars (Ellstrand, 1992). These conclusions are based on the synchronously dichogamous behavior of the flowers, the observation of nonreceptive stigmas during Stage II, the failure of caged trees of one cultivar to set many fruit, and the cohesive nature of avocado pollen (Davenport, 1986; Furon, 1963). Honeybees are considered the primary pollinator, especially in dry climates (Bergh, 1967; Clark and Clark, 1926; Furon, 1963; Gazit, 1976; Lecompte, 1961; Lesley and Bringhurst, 1951; McGregor, 1976; Papademetriou, 1976; Vithanage, 1990). Yet, ample evidence of self-pollination exists (Degani and Goldring, 1989; Degani et al., 1986).

Cool nights or overcast mornings delay opening and closing of

Received for publication 12 Nov. 1993. Accepted for publication 10 Mar. 1994. Florida Agricultural Experiment Station Journal series no. R-00724. This research was supported by a grant from the Florida Avocado Administrative Committee. We thank Bill Krome and N. Pal Brooks for use of their orchards during the study and Jim T. O'Neal for editorial assistance. The cost of publishing this paper was defrayed in part by the payment of page charges. Under postal regulations, this paper therefore must be hereby marked advertisement solely to indicate this fact. ${ }^{1}$ Associate professor. the morning flowers. Such delays may result in the occurrence of both Stage I and II flowers on trees of the same cultivar during the early afternoon (Robinson and Savage, 1926; Sedgley and Grant, 1983). As a consequence of this overlap of flowering stages, "close" pollination, i.e., pollen transfer from flower to flower in the same tree or cultivar (Peterson, 1955), may occur. This has been considered the primary mode of self-pollination, especially in solid blocks of one cultivar such as occurs in California (Bergh and Gustafson, 1958).

Contrary to this opinion, experiments conducted in Florida suggested that self-pollination occurs in some cultivars during Stage II through pollen transfer in flowers (Davenport, 1989). Stigmas of cultivars examined at the end of Stage I and II showed substantially more pollen deposited on Stage II flowers than on Stage I flowers. Fruit set appeared to correspond more closely to the Stage II pollination rates than to rates observed in Stage I. However, all flowers in that study were open-pollinated. The purpose of these experiments was to determine pollination rates at the two stages of floral opening under controlled conditions to verify whether self-pollination in the second opening is a significant event in several commercially important cultivars in Florida.

\section{Materials and Methods}

Environmental conditions. Environmental observations and flowering data were collected during an approximately 2-week period, representing the middle third of the flowering season of each cultivar. Temperature and relative humidity were continuously recorded with a calibrated, recording hygrothermograph placed $2 \mathrm{~m}$ above the ground in the orchard and verified daily with a sling psychrometer.

Plant material. Observations were conducted in three commercial avocado orchards with complementary cultivars planted in adjacent rows. Flowering occurred from early March through late April during both years of study. The start and end of flowering (anthesis of individual flowers on inflorescences) varied with each cultivar (Davenport, 1982). Fifteen-year-old 'Simmonds' (Type A) and 'Hardee' (Type B) trees, grafted on 'Waldin' seedling 
rootstocks and planted in alternate rows in a single orchard, were observed during the first year. Recording of daily observations of 'Hardee' began on the seventh day of 'Simmonds' observations, giving a 3-day overlap with common environmental conditions for the two cultivars. The second-year study included 'Simmonds' and 'Tonnage' (Type B) trees, planted in a second orchard, and 'Tower 2' (Type B) and 'Choquette' (Type A) trees, planted in a third orchard. The orchards were located several miles from each other. The trees were similar in age and were West Indian or West IndianGuatemalan hybrids selected because of their differing flowering types and commercial importance in Florida.

Flower behavior. Fifty flowers on each of five 'Simmonds' and 'Hardee' trees were tagged and then observed at hourly intervals during the first year of study. Stigma color was noted at the opening and closing of each stage. White stigmas were considered receptive whereas brown stigmas were not. In the second year, the proportion of white stigmas was noted at the close of both floral stages. Times of flower openings, anther dehiscence, and closings were recorded both years but only results from the first year are reported to conserve space.

Pollination studies. During the first year, four sets of branches consisting of 50 to 100 stem tips bearing inflorescences were randomly selected on each of five replicate trees and treated in one of four ways.

1) Stage I open-pollination. Branches were left uncovered, allowing open-pollination of flowers to occur. Flowers were collected from each branch at closing of Stage I flowers.

2) Stage II open-pollination. Branches were enclosed only during Stage I in frame-supported, cheesecloth bags to prevent pollination by flying insects. Care was taken to avoid bag contact with the flowers, so as not to damage the delicate organs. The cloth was removed daily at the end of this stage to facilitate pollination by flying insects during the Stage II. Flowers were collected at the end of Stage II and the branch was re-enclosed for the next day's experimental run.

3) Stage II bagged pollination. Branches were enclosed in cheesecloth bags during both Stage I and II. This treatment was included to determine if pollen transfer in flowers could occur during Stage II in the absence of flying insects. Flowers were collected at the close of Stage II.

4) Combined Stage I and II open-pollination. Branches were left uncovered continuously to allow open-pollination of flowers during both Stage I and II. Flowers were collected at the close of Stage II. This treatment represented events occurring naturally throughout the orchard. It was also analogous to the treatment reported in the preliminary study (Davenport, 1989).

All four individual branch treatments were installed on each of five replicate trees. Fifty flowers were collected daily at the appropriate time from each treatment on each of the five replicate trees. Flower pistils were harvested in the field with forceps, placed on microscope slides coated with a gel prepared as previously described (Davenport, 1989), covered with a glass slip, and viewed under a light microscope. The number of stigmas bearing pollen grains in each 50-flower sample was noted and the percentage was calculated for each treatment each day.

During the second year, 10 replicate trees each of 'Simmonds', 'Tonnage', 'Tower 2', and 'Choquette' were selected for uniformity. Sections of these trees were enclosed in $5.4 \mathrm{~m}^{3}$ cheesecloth bags supported by internal frames to prevent contact with inflorescences. The bags provided access to flowers without allowing entry of flying insects, such as bees or wasps, during sampling. Care was taken to insure that no such entry occurred. Branches were enclosed several days before the onset of flowering. Branches of similar size and location were tagged on the same trees to serve as open-pollinated controls.

Twenty-five to 30 flowers were collected daily at the close of the Stage I and Stage II floral openings in the bagged and openpollinated branches, and placed in vials containing FAA (50 parts formalin: 50 parts glacial acetic acid: 461 parts ethanol: 439 parts $\mathrm{H}_{2} \mathrm{O}$ ). The pistils were later separated from the corollas and placed on microscope slides (Davenport, 1989) as described above. Stigmas were observed under a light microscope and the number of stigmas bearing at least one pollen grain was recorded. No data were collected on days that resulted in delayed floral openings or closings due to cold fronts or at times when other grove activities prevented collection of flowers.

Fruit set study. Ten cheesecloth bags each were installed as described above on 'Simmonds', 'Tonnage', and 'Tower 2' branches before the onset of first flower anthesis. Comparable adjacent branches were tagged to serve as open-pollinated controls. The number of fruit set on each branch and the number of terminal shoots on the branches were recorded $\approx 1$ month after fruit set and again just before fruit maturity.

Statistical analysis. The experimental design was a randomized complete block. The mean percentage pollination observed in each treatment was calculated for each day. Following analysis of variance (ANOVA) on the arcsin transformed data, statistically significant differences among treatments were determined using Duncan's multiple range test in the first year and Student's $t$ test in the second year.

\section{Results}

Temperatures and relative humidities were typical for March and April during both years of the study. Except for during passage of periodic cold fronts, maximum daily temperatures ranged from 27 to $31 \mathrm{C}$ and minimum night temperatures were $\approx 20 \mathrm{C}$. Periodic cold fronts typically brought temperatures down to near 20C during the days and between 10 and $18 \mathrm{C}$ during the night. Relative humidities during the day were $\approx 80 \%$ except following cold front passage when it dropped to as low as $40 \%$.

Table 1. Diural means and extremes of temperature and relative humidity in a Homestead, Fla., avocado orchard during late Mar. 1986.

\begin{tabular}{lccccccccc}
\hline \hline & \multicolumn{4}{c}{ Temp } & & \multicolumn{4}{c}{ Relative humidity } \\
\cline { 2 - 3 } \cline { 8 - 9 } Day & MD $^{z}$ & Max & MN $^{y}$ & Min & & MD & Min & MN & Max \\
\hline 1 & 26.7 & 31.7 & 20.6 & 19.4 & & 81 & 51 & 98 & 98 \\
2 & 26.1 & 30.0 & 21.1 & 19.4 & & 80 & 65 & 98 & 98 \\
3 & 26.1 & 28.3 & 20.6 & 18.9 & & 76 & 62 & 98 & 98 \\
4 & 25.6 & 27.2 & 23.9 & 23.9 & & 86 & 71 & 94 & 98 \\
5 & 27.8 & 30.0 & 25.0 & 23.3 & & 72 & 60 & 93 & 97 \\
6 & 25.6 & 27.2 & 21.1 & 20.6 & & 86 & 74 & 98 & 98 \\
7 & 26.1 & 28.9 & 23.3 & 22.8 & & 80 & 70 & 97 & 98 \\
8 & 26.7 & 28.3 & 23.0 & 21.7 & & 78 & 69 & 94 & 94 \\
9 & 27.8 & 30.6 & 22.8 & 22.2 & & 79 & 52 & 93 & 94 \\
10 & 20.6 & 23.3 & 15.0 & 13.3 & & 70 & 48 & 90 & 94 \\
11 & 22.8 & 24.4 & 17.7 & 16.1 & & 60 & 40 & 80 & 94 \\
12 & 22.8 & 24.4 & 18.3 & 17.7 & & 75 & 58 & 93 & 94 \\
\hline
\end{tabular}

${ }^{\mathrm{z}}$ Mean day readings taken from dawn to sunset.

yMean night readings taken from sunset to dawn. 
Table 2. Approximate times (h) of onset of daily opening, anther dehiscence (AD), and closing of 'Simmonds' (Type A) avocado flowers in Florida during first year of study. Days correspond to days presented in Table $1 .{ }^{\mathrm{z}}$

\begin{tabular}{lcccccccc}
\hline \hline & \multicolumn{7}{c}{ Day } \\
\cline { 2 - 8 } Stage & 1 & 2 & 3 & 4 & 5 & 6 & 7 & 8 \\
\hline I Opening & 1115 & 1000 & 0930 & 1000 & 0900 & 1000 & 0900 & 0900 \\
I Closing & 1300 & 1300 & 1300 & 1200 & 1200 & 1200 & 1200 & 1200 \\
II Opening & 1300 & 1300 & 1300 & 1230 & 1230 & 1215 & 1230 & 1215 \\
AD & 1500 & 1500 & 1600 & 1500 & 1615 & 1500 & 1500 & 1500 \\
II Closing & 1730 & 1800 & 1830 & 1800 & 1830 & 1815 & 1830 & 1800 \\
\hline
\end{tabular}

${ }^{\mathrm{z}}$ Actual openings and closings times varied by 15 to 30 min depending on microclimate of individual flowers.

Table 3. Approximate times (h) of onset of daily opening, anther dehiscence (AD), and closing of 'Hardee' (Type B) avocado flowers in Florida during first year of study. Days correspond to days presented in Table $1 .{ }^{\mathrm{z}}$

\begin{tabular}{lcccccr}
\hline & \multicolumn{7}{c}{ Day } \\
\cline { 2 - 7 } Stage & 7 & 8 & 9 & 10 & 11 & 12 \\
\hline II Opening & 0900 & 0900 & 0900 & 1100 & 0900 & 0900 \\
AD & 1000 & 1000 & 1000 & 1400 & 1000 & 1000 \\
II Closing & 1215 & 1200 & 1200 & 1600 & 1200 & 1200 \\
I Opening & 1515 & 1515 & 1500 & --- & 1515 & 1500 \\
I Closing & 1800 & 1800 & 1800 & --- & 1800 & 1800 \\
\hline
\end{tabular}

${ }^{\mathrm{z}}$ Actual openings and closings times varied by 15 to 30 min depending on microclimate of individual flowers.

The daily temperatures and relative humidities recorded during the 12-day period in late Mar. 1986 of the first year's experiment are presented in Table 1 to demonstrate correlation of daily environmental conditions with flowering behavior of 'Simmonds' and 'Hardee' over the same period (Tables 2 and 3). Overlap of flowering Stages I and II did not occur even during low temperature extremes that existed on day 10. For example, Stage II floral opening of 'Hardee' was delayed by $2 \mathrm{~h}$. Closure was delayed by $4 \mathrm{~h}$ and Stage I opening did not occur during daylight hours; therefore, pollination data were not recorded. On days not influenced by cold fronts, the timing of floral openings and closings were typical of A and B types. Similar relationships existed for all cultivars examined during second year's study (data not shown).

Closing of Stage I flowers at about solar noon coincided with opening of Stage II flowers in Type A cultivars. Opening of Stage I flowers in the afternoon of Type B cultivars were, at times, delayed. Anther dehiscence never coincided with open Stage I flowers in a cultivar during either year of study (Tables 2 and 3). Typically, cool temperatures during cold fronts delayed both stages such that there was never overlap of flowering stages even though flowers remained open hours longer.

The number of flowers bearing white stigmas through Stage II floral openings varied with cultivar. For example, 'Simmonds' flowers during the first year had $49 \%$ white stigmas at the opening of Stage II and 33\% at its close (Table 4). The majority of 'Hardee' stigmas $(86.1 \%)$ were white at the beginning of Stage II, and most (78.7\%) were still white by closing (Table 5). It should be noted that stigma desiccation began during Stage I. Moreover, the number of white stigmas at the close of Stage II varied substantially from day to day, ranging from $4 \%$ to $42 \%$ in 'Simmonds' and from $71 \%$ to $90 \%$ in 'Hardee'. Daily overall means for all four cultivars studied the following year were similar (data not presented).

Despite the different experimental designs used each year, we found substantially lower pollination rates in Stage I than in Stage II floral openings (Tables 6 through 11). For example, during the first year, an average of only $0.7 \%$ of the 'Simmonds' flowers were

Table 4. Proportion of white stigmas (\%) observed during Stage I and II openings and closings of 'Simmonds' (Type A) avocado flowers in Florida during first year of study. Days correspond to days presented in Table $1 .^{\mathrm{z}}$

\begin{tabular}{|c|c|c|c|c|c|c|c|c|c|}
\hline \multirow[b]{2}{*}{ Stage } & \multicolumn{8}{|c|}{ Day } & \multirow[b]{2}{*}{ Mean } \\
\hline & 1 & 2 & 3 & 4 & 5 & 6 & 7 & 8 & \\
\hline I Opening & 94.4 & 91.2 & 91.2 & 96.0 & 100.0 & 86.8 & 95.2 & 97.2 & $94.7 \mathrm{a}$ \\
\hline I Closing & 94.4 & 86.8 & 83.6 & 44.4 & 76.8 & 86.8 & 88.8 & 86.8 & $83.2 \mathrm{~b}$ \\
\hline II Opening & 73.2 & 56.4 & 22.8 & 56.0 & 32.0 & 15.6 & 82.4 & 55.2 & $49.3 \mathrm{c}$ \\
\hline II Closing & 28.0 & 18.4 & 4.0 & 41.6 & 25.2 & 24.0 & 36.0 & 35.2 & $33.3 \mathrm{~d}$ \\
\hline
\end{tabular}

${ }^{{ }^{2}}$ Daily means were determined from percentages of white stigmas among 50 flowers per tree from five trees on each day. Overall means are averages of daily means. Separation of arcsin-transformed means by Duncan's multiple range test, $P=0.05$.

Table 5. Proportion of white stigmas (\%) observed during Stage I and II openings and closings of 'Hardee' (Type B) avocado flowers in Florida during first year of study. Days correspond to days presented in Table $1 .{ }^{\mathrm{z}}$

\begin{tabular}{|c|c|c|c|c|c|c|c|}
\hline \multirow[b]{2}{*}{ Stage } & \multicolumn{6}{|c|}{ Day } & \multirow[b]{2}{*}{ Mean } \\
\hline & 7 & 8 & 9 & 10 & 11 & 12 & \\
\hline I Opening & 100.0 & 99.6 & 98.0 & --- & 99.8 & 100.0 & $99.5 \mathrm{a}$ \\
\hline I Closing & 98.8 & 97.2 & 96.0 & --- & 98.1 & 98.0 & $97.6 \mathrm{a}$ \\
\hline II Opening & 86.8 & 70.0 & 80.0 & 88.4 & 96.0 & 95.6 & $86.1 \mathrm{~b}$ \\
\hline II Closing & 72.0 & 79.2 & 70.8 & 72.4 & 87.6 & 90.4 & $78.7 \mathrm{~b}$ \\
\hline
\end{tabular}

${ }^{\mathrm{z}}$ Daily means were determined from percentages of white stigmas among 50 randomly selected flowers per tree in five replicate trees at each observation day. Overall means are averages of daily means. Separation of arcsin-transformed means by Duncan's multiple range test, $P=0.05$. 
Table 6. Comparison of pollination rates (\%) in Stage I and II of 'Simmonds' avocado flowers in Florida during first year of study. ${ }^{\mathrm{z}}$

\begin{tabular}{|c|c|c|c|c|c|c|c|c|c|}
\hline \multirow[b]{2}{*}{ Treatment $^{\mathrm{y}}$} & \multicolumn{8}{|c|}{ Day } & \multirow[b]{2}{*}{ Mean } \\
\hline & 1 & 2 & 3 & 4 & 5 & 6 & 7 & 8 & \\
\hline 1 & 0.4 & 1.2 & 1.2 & 0.8 & 1.2 & 0.4 & 0.4 & 0.4 & $0.7 \mathrm{a}$ \\
\hline 2 & 3.2 & 17.2 & 20.8 & 13.6 & 7.2 & 21.6 & 20.8 & 31.2 & $15.1 \mathrm{~b}$ \\
\hline 3 & 23.2 & 19.6 & 33.6 & 8.4 & 7.2 & 19.2 & 15.6 & 28.4 & $17.2 \mathrm{~b}$ \\
\hline 4 & 26.4 & 18.8 & 28.0 & 16.8 & 7.2 & 25.6 & 18.8 & 26.4 & $18.7 \mathrm{~b}$ \\
\hline $\begin{array}{l}\% \text { Stage } \mathrm{II}^{\mathrm{x}} \\
\text { pollination }\end{array}$ & 98.5 & 93.7 & 95.4 & 95.3 & 83.4 & 98.5 & 97.9 & 98.5 & 96.7 \\
\hline
\end{tabular}

${ }^{\mathrm{z} D a i l y ~ m e a n s ~ w e r e ~ d e t e r m i n e d ~ f r o m ~ p e r c e n t a g e s ~ o f ~ s t i g m a s ~ b e a r i n g ~ p o l l e n ~ a m o n g ~} 50$ randomly selected flowers per treatment branch from five trees at each observation period. Overall means are averages of daily treatment means. Separation of arcsintransformed means by Duncan's multiple range test, $P=0.05$.

yTreatments 1 to 4 are: 1) Stage I open-pollination, 2) Stage II open-pollination, 3) Stage II enclosed-pollination, 4) combined Stage I and II open-pollination.

xPercent of total number of pollinated flowers which were self-pollinated in Stage II.

Table 7. Comparison of pollination rates (\%) in Stage I and II of 'Hardee' avocado flowers in south Florida during first year of study. ${ }^{\mathrm{z}}$

\begin{tabular}{|c|c|c|c|c|c|c|c|}
\hline \multirow[b]{2}{*}{ Treatment $^{\mathrm{y}}$} & \multicolumn{6}{|c|}{ Day } & \multirow[b]{2}{*}{ Mean } \\
\hline & 7 & 8 & 9 & 10 & 11 & 12 & \\
\hline 1 & 10.8 & 9.2 & 6.0 & --- & --- & 18.4 & $11.1 \mathrm{a}$ \\
\hline 2 & 92.4 & 63.6 & 65.6 & --- & 56.4 & 66.8 & $69.2 \mathrm{~b}$ \\
\hline 3 & 80.4 & 58.0 & 49.2 & --- & 64.0 & 68.0 & $63.9 \mathrm{~b}$ \\
\hline 4 & 84.0 & 71.2 & 54.0 & --- & 66.0 & 72.8 & $69.6 \mathrm{~b}$ \\
\hline $\begin{array}{l}\% \text { Stage } \text { II }^{\mathrm{x}} \\
\text { pollination }\end{array}$ & 87.2 & 87.1 & 88.9 & --- & --- & 74.8 & 85.5 \\
\hline
\end{tabular}

${ }^{\mathrm{Z}}$ Daily means were determined from percentages of stigmas bearing pollen among 50 randomly selected flowers per treatment branch in five replicate trees at each observation day. Overall means are averages of daily and treatment means. Separation of arcsin-transformed means by Duncan's multiple range test, $P=0.05$.

yTreatments 1 to $4:$ 1) Stage I open-pollination, 2) Stage II open-pollination, 3) Stage II enclosed-pollination, 4) combined Stage I and II open-pollination.

${ }^{x}$ Percent of the total number of pollinated flowers pollinated in Stage II (self-pollinated).

Table 8. Daily mean percent \pm SD of 'Simmonds' (Type A) avocado flowers with at least one pollen grain deposited on the stigma in either Stage I or II of open-pollinated or inflorescences protected by cheesecloth bags during second year of study.

\begin{tabular}{|c|c|c|c|c|c|}
\hline \multirow[b]{2}{*}{ Date } & \multicolumn{2}{|c|}{ Stage I } & \multicolumn{2}{|c|}{ Stage II } & \multirow{2}{*}{$\begin{array}{l}\% \text { Stage } I^{2} \\
\text { pollination }\end{array}$} \\
\hline & Open & Bagged & Open & Bagged & \\
\hline $3 / 07 / 88$ & $0.7 \pm 2.0$ & $0.0 \pm 0.0$ & --- & --- & --- \\
\hline $3 / 08 / 88$ & $1.1 \pm 2.3$ & $0.4 \pm 1.3$ & $7.7 \pm 4.8$ & $6.4 \pm 5.0$ & 86 \\
\hline $3 / 09 / 88$ & $1.1 \pm 2.3$ & $0.0 \pm 0.0$ & $9.4 \pm 4.4$ & $4.8 \pm 4.4$ & 89 \\
\hline $3 / 10 / 88$ & $1.0 \pm 2.1$ & $0.0 \pm 0.0$ & $9.5 \pm 6.7$ & $5.2 \pm 4.6$ & 92 \\
\hline $3 / 11 / 88$ & $0.4 \pm 1.3$ & $0.0 \pm 0.0$ & $13.8 \pm 9.4$ & $5.8 \pm 5.9$ & 97 \\
\hline $3 / 12 / 88$ & $0.8 \pm 1.8$ & $0.0 \pm 0.0$ & $5.3 \pm 3.9$ & $3.1 \pm 3.9$ & 85 \\
\hline $3 / 14 / 88$ & $0.0 \pm 0.0$ & $0.0 \pm 0.0$ & $8.2 \pm 7.8$ & $7.1 \pm 5.4$ & 100 \\
\hline $3 / 15 / 88$ & $0.7 \pm 0.5$ & $0.0 \pm 0.0$ & --- & --- & --- \\
\hline $3 / 16 / 88$ & $1.8 \pm 2.5$ & $0.0 \pm 0.0$ & $7.7 \pm 5.0$ & $1.6 \pm 2.0$ & 75 \\
\hline $3 / 22 / 88$ & $0.7 \pm 1.4$ & $0.0 \pm 0.0$ & --- & --- & --- \\
\hline $3 / 23 / 88$ & $0.4 \pm 1.2$ & $0.0 \pm 0.0$ & $10.3 \pm 3.5$ & $5.2 \pm 3.5$ & 96 \\
\hline $3 / 24 / 88$ & $0.7 \pm 1.4$ & $0.0 \pm 0.0$ & $7.9 \pm 6.9$ & $4.3 \pm 3.5$ & 90 \\
\hline $3 / 28 / 88$ & $2.0 \pm 2.7$ & $0.0 \pm 0.0$ & --- & --- & --- \\
\hline $3 / 30 / 88$ & $0.4 \pm 1.2$ & $0.0 \pm 0.0$ & $5.9 \pm 3.6$ & $2.8 \pm 5.0$ & 92 \\
\hline $3 / 31 / 88$ & $2.3 \pm 3.4$ & $0.0 \pm 0.0$ & --- & --- & --- \\
\hline Mean & $0.9 \pm 0.6$ & $0.0 \pm 0.1$ & $8.6 \pm 2.4$ & $4.6 \pm 1.7$ & $90.2 \pm 7.1$ \\
\hline
\end{tabular}

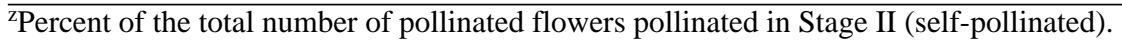

pollinated during Stage I (Table 6). Cross-pollination occurred during Stage I because only pollen from Stage II flowers in the adjacent row of the complementary cultivar, Hardee, was available. Higher mean pollination rates $(8.9 \%)$ were observed in openpollinated Stage I flowers of 'Hardee' (Table 7). Substantially more bee activity was observed on the latter cultivar, which may have accounted for the greater pollination rates. In contrast, pollination was substantially greater during Stage II than Stage I in both cultivars. Pollination of flowers, which had been protected from cross-pollination by cheesecloth bags during Stage I but 
Table 9. Daily mean percent \pm SD of 'Tonnage' (Type B) avocado flowers with at least one pollen grain deposited on the stigma in either Stage I or II of open-pollinated or in bagged inflorescences during second year of study.

\begin{tabular}{|c|c|c|c|c|c|}
\hline \multirow[b]{2}{*}{ Date } & \multicolumn{2}{|c|}{ Stage I } & \multicolumn{2}{|c|}{ Stage II } & \multirow{2}{*}{$\begin{array}{l}\% \text { Stage } \mathrm{II}^{2} \\
\text { pollination }\end{array}$} \\
\hline & Open & Bagged & Open & Bagged & \\
\hline $3 / 22 / 88$ & --- & $0.0 \pm 0.0$ & $35.3 \pm 19.3$ & $27.7 \pm 9.1$ & 100 \\
\hline $3 / 23 / 88$ & $0.0 \pm 0.0$ & $0.0 \pm 0.0$ & $50.7 \pm 10.9$ & $47.5 \pm 10.1$ & 100 \\
\hline $3 / 24 / 88$ & $2.2 \pm 2.7$ & $0.0 \pm 0.0$ & $37.4 \pm 18.0$ & $29.5 \pm 10.5$ & 94 \\
\hline $3 / 28 / 88$ & $1.8 \pm 3.1$ & $0.0 \pm 0.0$ & $50.5 \pm 10.2$ & $38.6 \pm 12.2$ & 98 \\
\hline $3 / 29 / 88$ & $1.9 \pm 2.0$ & $0.0 \pm 0.0$ & $40.2 \pm 9.1$ & $28.0 \pm 8.3$ & 95 \\
\hline $3 / 30 / 88$ & $0.3 \pm 1.0$ & $0.0 \pm 0.0$ & $49.2 \pm 9.1$ & $38.5 \pm 12.3$ & 99 \\
\hline $3 / 31 / 88$ & $1.8 \pm 1.8$ & $0.0 \pm 0.0$ & $44.7 \pm 16.6$ & $41.4 \pm 11.2$ & 97 \\
\hline $4 / 04 / 88$ & $2.0 \pm 2.0$ & $0.0 \pm 0.0$ & $35.2 \pm 10.4$ & $28.5 \pm 8.6$ & 95 \\
\hline $4 / 05 / 88$ & $1.5 \pm 2.7$ & $0.0 \pm 0.0$ & $27.7 \pm 11.5$ & $24.6 \pm 9.6$ & 94 \\
\hline $4 / 06 / 88$ & $1.1 \pm 1.7$ & $0.0 \pm 0.0$ & $30.0 \pm 12.0$ & $31.5 \pm 13.3$ & 96 \\
\hline $4 / 07 / 88$ & $2.3 \pm 2.7$ & $0.0 \pm 0.0$ & $40.2 \pm 13.2$ & $7.1 \pm 7.4$ & 94 \\
\hline $4 / 08 / 88$ & $1.0 \pm 1.7$ & $0.0 \pm 0.0$ & $23.8 \pm 10.6$ & $31.8 \pm 6.9$ & 95 \\
\hline $4 / 11 / 88$ & --- & --- & $14.0 \pm 6.0$ & $15.2 \pm 4.1$ & --- \\
\hline $4 / 12 / 88$ & --- & --- & $25.6 \pm 6.4$ & $35.3 \pm 12.5$ & --- \\
\hline $4 / 13 / 88$ & --- & --- & $19.0 \pm 6.5$ & $19.8 \pm 9.0$ & --- \\
\hline Mean & $1.4 \pm 0.8$ & $0.0 \pm 0.0$ & $34.9 \pm 11.4$ & $29.7 \pm 10.4$ & $96.4 \pm 2.3$ \\
\hline
\end{tabular}

${ }^{\text {ZPercent }}$ of the total number of flowers pollinated in Stage II (self-pollinated).

Table 10. Daily mean percent \pm SD of 'Tower 2' (Type B) avocado flowers with at least one pollen grain deposited on the stigma in either Stage I or II of open-pollinated or in bagged inflorescences during second year of study.

\begin{tabular}{|c|c|c|c|c|c|}
\hline \multirow[b]{2}{*}{ Date } & \multicolumn{2}{|c|}{ Stage I } & \multicolumn{2}{|c|}{ Stage II } & \multirow{2}{*}{$\begin{array}{l}\% \text { Stage } \mathrm{II}^{2} \\
\text { Pollination }\end{array}$} \\
\hline & Open & Bagged & Open & Bagged & \\
\hline $4 / 06 / 88$ & $0.5 \pm 1.6$ & $0.0 \pm 0.0$ & $11.4 \pm 9.2$ & $4.7 \pm 3.4$ & 95 \\
\hline $4 / 07 / 88$ & $0.4 \pm 1.3$ & $0.0 \pm 0.0$ & --- & $5.5 \pm 5.4$ & 97 \\
\hline $4 / 08 / 88$ & $1.0 \pm 2.2$ & $0.0 \pm 0.0$ & $6.7 \pm 4.6$ & $5.1 \pm 6.6$ & 88 \\
\hline $4 / 09 / 88$ & --- & --- & $2.2 \pm 3.6$ & $3.2 \pm 4.8$ & --- \\
\hline $4 / 10 / 88$ & --- & --- & $3.1 \pm 2.4$ & $1.5 \pm 2.0$ & --- \\
\hline $4 / 11 / 88$ & $1.1 \pm 2.4$ & $0.0 \pm 0.0$ & $5.7 \pm 4.3$ & $4.4 \pm 4.7$ & 79 \\
\hline $4 / 12 / 88$ & --- & --- & $6.4 \pm 7.5$ & $5.2 \pm 6.6$ & -- \\
\hline $4 / 13 / 88$ & --- & --- & $2.2 \pm 2.4$ & $4.6 \pm 6.4$ & --- \\
\hline Mean & $0.8 \pm 0.4$ & $0.0 \pm 0.0$ & $5.4 \pm 3.2$ & $4.3 \pm 1.3$ & $89.6 \pm 8.1$ \\
\hline
\end{tabular}

${ }^{\mathrm{z}}$ Percent of the total number of flowers pollinated in Stage II (self-pollinated).

allowed to open-pollinate in Stage II (Treatment 2), was $15.1 \%$ in 'Simmonds' (Table 6) and 69.0\% in 'Hardee' (Table 7). Openpollination during both stages (Treatment 4 ) resulted in $18.7 \%$ and $69.6 \%$ in 'Simmonds' and 'Hardee', respectively. Pollination rates of enclosed Stage II flowers were similar to those for openpollinated flowers on both cultivars (Tables 6 and 7). The overall number of flowers pollinated during Stage II was $96 \%$ and $85.5 \%$ of the total number of 'Simmonds' and 'Hardee' flowers pollinated (Stages I and II), respectively. Pollination rates varied substantially from day to day (Tables 6 and 7). Daily variations in pollination rates, however, did not correlate with variations in proportion of white stigmas (Tables 4 and 5).

Daily pollination rates in open-pollinated, Stage I flowers of 'Simmonds' in the second year (Table 8) were similar to those obtained in the first year (Table 6). The mean pollination rate was $0.92 \%$. Stage I flowers that were continuously enclosed in cheesecloth bags received no pollen except for one flower on 1 day. The amount of open-pollination in Stage II (8.6\%) was less than that obtained in the previous year in the other orchard. Pollination of flowers on enclosed branches, however, was about half that of open-pollinated flowers.

Results on the other cultivars were similar. 'Tonnage', 'Tower 2', and 'Choquette' flowers that were open-pollinated in Stage I had mean pollination rates of $1.4 \%, 0.74 \%$, and $1.0 \%$, respectively
(Tables 8 through 11). No pollination took place on Stage I enclosed flowers of the examined cultivars. Open-pollination of Stage II flowers was $35.0 \%, 5.4 \%$, and $22.6 \%$ in 'Tonnage', 'Tower 2', and 'Choquette', respectively. The overall rates of pollination on Stage II flowers on 'Tonnage' (31.9\%) and 'Tower 2 ' $(4.3 \%)$ enclosed flowers were not significantly different from those in open-pollinated flowers (Table 12). Data on enclosed 'Choquette' flowers were not collected due to time constraints.

Fruit set on enclosed branches was determined $\approx 1$ month after termination of flowering of 'Simmonds', 'Tonnage', and 'Tower 2 ' (Table 13). Fruit size ranged from 1 to $2.5 \mathrm{~cm}$. The mean number of fruits per terminal on open-pollinated branches varied from a high of 0.25 in 'Tonnage' to a low of 0.05 in 'Tower 2 '. The number of fruits found on enclosed branches was similar to those found on open-pollinated branches in 'Tonnage' and 'Tower 2'. However, 'Simmonds' fruit set on open-pollinated branches was double that found on enclosed branches. Few fruits remained at maturity in all cultivars on either enclosed or open branches.

\section{Discussion}

Outcrossing has been assumed to be the primary mode of pollination in avocado because of its synchronously dichogamous flowering behavior, especially in interplanted orchards (Daven- 
Table 11. Daily mean percent \pm SD of 'Choquette' (Type A) flowers with at least one pollen grain deposited on the stigma at the end of either Stage I or II of open-pollinated flowers during second year of study.

\begin{tabular}{lccc}
\hline \hline Date & Stage 1 & Stage II & $\begin{array}{c}\text { \% Stage II } \\
\text { pollination }\end{array}$ \\
\hline $4 / 07 / 88$ & --- & $13.3 \pm 7.2$ & --- \\
$4 / 08 / 88$ & $1.7 \pm 3.0$ & $18.7 \pm 10.0$ & 91 \\
$4 / 09 / 88$ & $0.4 \pm 1.2$ & $21.1 \pm 14.0$ & 98 \\
$4 / 10 / 88$ & $1.8 \pm 3.4$ & $19.3 \pm 4.6$ & 91 \\
$4 / 11 / 88$ & $3.0 \pm 4.6$ & $38.8 \pm 9.2$ & 93 \\
$4 / 12 / 88$ & $0.8 \pm 1.6$ & $24.8 \pm 10.3$ & 97 \\
$4 / 13 / 88$ & $1.2 \pm 2.6$ & $22.3 \pm 6.9$ & 95 \\
$4 / 14 / 88$ & $1.3 \pm 2.1$ & $26.2 \pm 8.5$ & 96 \\
$4 / 15 / 88$ & $0.9 \pm 1.8$ & $24.0 \pm 7.7$ & 97 \\
$4 / 16 / 88$ & $0.4 \pm 1.2$ & $24.1 \pm 8.2$ & 98 \\
$4 / 17 / 88$ & $1.2 \pm 2.1$ & $22.7 \pm 5.0$ & 95 \\
$4 / 18 / 88$ & $0.4 \pm 1.2$ & $21.4 \pm 7.4$ & 98 \\
$4 / 19 / 88$ & $0.0 \pm 0.0$ & $21.8 \pm 6.6$ & 100 \\
$4 / 20 / 88$ & $0.0 \pm 0.0$ & $17.9 \pm 5.6$ & 100 \\
Mean & $1.0 \pm 0.8$ & $22.6 \pm 5.7$ & $96.1 \pm 3.0$
\end{tabular}

$\overline{\text { Percent }}$ of the total number of flowers pollinated in Stage II (selfpollinated).

Table 12. Statistical comparison of overall means of pollen deposition by cultivar among stages and treatments during second year of study using Student's $t$ test (95\% level).

\begin{tabular}{|c|c|c|c|c|}
\hline Cultivar & Treatment & Stage I & Stage II & Significance \\
\hline \multirow[t]{2}{*}{ Simmonds } & Open & 0.9 & 8.6 & $* *$ \\
\hline & Bagged & 0.03 & 4.6 & $* *$ \\
\hline Significance & & $* *$ & $* *$ & \\
\hline \multirow[t]{2}{*}{ Tonnage } & Open & 1.4 & 35.0 & $* *$ \\
\hline & Bagged & 0.0 & 29.7 & $* *$ \\
\hline Significance & & $* *$ & NS & \\
\hline \multirow[t]{2}{*}{ Tower 2} & Open & 0.8 & 5.4 & $* *$ \\
\hline & Bagged & 0.0 & 4.3 & $* *$ \\
\hline Significance & & $*$ & NS & \\
\hline
\end{tabular}

ss, ${ }^{* * *}$ Nonsignificant or significant at $P \leq 0.05$ or 0.01 , respectively.

Table 13. Average fruit set on representative lower branches 1 month after flowering of three avocado cultivars during second year of study. Flowers on branches were either open-pollinated or self-pollinated in cheesecloth bags.

\begin{tabular}{lrrrrr}
\hline \hline & \multicolumn{2}{c}{ Fruit } & & \multicolumn{2}{c}{ Fruit/terminal } \\
\cline { 2 - 3 } \cline { 5 - 6 } Cultivar & \multicolumn{1}{c}{ Bagged } & \multicolumn{1}{c}{ Open } & & Bagged & Open \\
\hline Simmonds & $9.4 \pm 1.9$ & $17.8 \pm 1.9$ & & $0.12 \pm 0.01^{*_{\mathrm{*} Z}}$ & $0.23 \pm 0.02^{* *_{\mathrm{Z}}}$ \\
Tonnage & $11.7 \pm 1.9$ & $12.8 \pm 2.1$ & & $0.22 \pm 0.03^{\mathrm{NS}}$ & $0.25 \pm 0.03^{\mathrm{NS}}$ \\
Tower 2 & $2.3 \pm 1.0$ & $3.4 \pm 0.9$ & & $0.03 \pm 0.01^{\mathrm{NS}}$ & $0.05 \pm 0.01^{\mathrm{NS}}$ \\
& & & & &
\end{tabular}

${ }^{\mathrm{z}}$ Analysis of variance comparing fruit set between bagged or openpollinated flowers.

Ns, ${ }^{* *}$ Nonsignificant or significant at $P \leq 0.01$.

port, 1986). The assumption that pollen must be deposited on stigmas during Stage I, because the stigma was considered no longer receptive to pollen during Stage II, led to the notion that selfpollination could only occur when there is an overlap of flowering stages (Bergh and Gustafson, 1958). Our experiments do not support this conclusion. The results of this and a previous study (Davenport, 1989) clearly indicate that a substantial portion (30\% to $80 \%$ ) of stigmas remain white through Stage II floral openings (Tables 1 and 2, data from second year not presented). Daily variation not withstanding, pollination rates during Stage II were consistent with the number of white stigmas available (Tables 3 and 4). Loss of stigma receptivity to pollen is well known (Davenport, 1986; Nirody, 1922; Stout, 1923) but the causal factors are not; nor is it known why 'Hardee' styles are more resistant to desiccation than those of other cultivars. Large differences in the daily proportion of white stigmas are likely due to differences in the desiccation potential of the floral microenvironment. Stigma desiccation also occurred with some degree of variability during Stage I and during the overnight interval between floral openings (Tables 4 and 5). Moreover, contrary to the findings of Sedgley (1977a), we have found in recent studies that white stigmas in Stage II are receptive, promote pollen germination, and support pollen tube growth to the ovule as efficiently as those pollinated during Stage I (F. Embert and T.L. Davenport, unpublished data). Pollen did not adhere to brown stigmas.

Generally, low bee activity was noted in the orchards of all cultivars examined except 'Hardee,' especially during cool days. Even in the mixed orchards, bees visited 'Hardee' flowers more often than 'Simmonds'. Few bees visited 'Simmonds' flowers during both years of study or the other three cultivars tested the second year. Wasps were present in small numbers. Although we did not confirm that bees are the main pollinator, it is likely they are the primary pollinator of Stage I flowers since, even though their numbers on the tree were low, they were the most frequent visitors.

Low temperatures and rainy, overcast days associated with cold fronts early in the flowering seasons further inhibited the light bee activity. Cold fronts also drastically altered the timing of floral openings and closings as has been reported elsewhere (Sedgley 1977a, Sedgley and Grant, 1983). Delays in floral openings and closings due to these conditions never caused overlap of stages. Instead, both stages were delayed so that transfer of pollen from flowers of one stage to the other within cultivar was impossible. Moreover, because pollen tube growth is acutely sensitive to temperature (Sedgley, 1977b), it is unlikely that any pollination that may have occurred would have resulted in successful fertilization of the ovule. Lack of fruit set commonly observed during these periods supports this suggestion. Temperatures were generally optimum (except during cold fronts) for proper avocado flowering behavior (Sedgley, 1977b; Sedgley and Grant, 1983). Overlapping flowering stages occurred rarely and only on warm days with cooler than normal nights. Such overlaps were never more than about 30 min in length and never coincided with the presence of pollen in Stage II flowers, i.e., post dehiscence. Thus, close pollination, i.e., pollen transfer from flowers on the same tree or cultivar, did not occur during the 2-year study.

Overall pollination rates during Stage I were low $(\approx 1 \%)$ in all cultivars studied except for 'Hardee' (Tables 6 through 11), which received more bee visitations than the others. These rates accounted for only $5 \%$ or less of the pollinated flowers. Consistent with earlier-published results obtained on open-pollinated flowers (Davenport, 1989), the results obtained during the 2 years reported here demonstrated that avocado pollination takes place primarily in Stage II flowers of Florida-grown avocados. Generally, >95\% of the pollinated flowers were pollinated in Stage II and overall pollination rates were consistent with the overall number of white stigmas available for pollination. As observed earlier (Davenport, 1989), the amount of pollination differed each day but appeared to have little correlation with relative humidity or insect activity. Stigma desiccation potential is likely influenced by a combination of factors including vapor pressure, wind, and solar radiation directly impacting flowers.

Contrary to the generally accepted concept that "self" pollina- 
tion can only occur between flowers on the same tree or cultivar when flowering stages overlap, our data clearly demonstrate that the primary mode of pollen transfer was by true self-pollination within flowers. At no time did floral openings overlap in openpollinated flowers when pollen was available for transfer. Moreover, the great majority of pollen arrived during Stage II, as indicated by the high pollination rates noted in Treatment 2 flowers compared to those in Treatment 1 of both 'Simmonds' and 'Hardee' during the first year and by comparison of pollination results at the end of Stage I and Stage II flowers on open-pollinated branches of 'Simmonds', 'Tonnage', 'Tower 2', and 'Choquette' during the second year. Results of the first year experiments, which eliminated the possibility of pollen transfer to flowers during Stage I but allowed open-pollination of Stage II flowers, proved that pollen transfer was occurring primarily during Stage II. For example, the pollination rates of open-pollinated flowers in both stages were the same as those which were allowed to open-pollinate only during Stage II.

Large flying insects were necessary for cross-pollination in Stage I. Because there was no pollen available for transfer to Stage I flowers in the bags at any time, pollination during this opening was presumed to be zero during the first year of experiments. The second season's results in which enclosed flowers were sampled at the close of Stage I verified this assumption. Virtually no pollination took place during Stage I on enclosed branches, compared to the typical levels (about 1\%) taking place in open-pollinated branches. We noted one anomalous pollination event taking place on one flower of 'Simmonds' on a windy day (Table 8). No flying insects were in the bag at any time. We, therefore, presume that pollen drifting in the wind from the adjacent row of the complementary cultivar Tonnage may have been responsible. Otherwise the cheesecloth bags effectively prevented pollination by flying insects.

The same lack of flying insect interaction can be inferred in the flowers enclosed in cheesecloth bags during both Stage I and II openings. Despite this, pollen transfer took place during Stage II at rates similar to those of flowers that were open-pollinated. Considering the lack of overlap of floral stages and the lack of available pollinators, pollen deposition was accomplished predominantly across the millimeter distance from anthers to stigma within flowers and, perhaps, to a lesser extent from nearby flowers in the bags. These results demonstrate that not only are flowers selfed during Stage II, but also that flying insect pollinators are not required. These observations lead to the conclusion that the majority of avocado flower pollination in Florida is accomplished by wind, gravity, or possibly thrips transfer of pollen within flowers. The abundance of thrips on avocado flowers in Florida has been noted by Stout and Savage (1925), Davenport (1986), and Fisher and Davenport (1989).

Normal fruit set on enclosed branches of 'Simmonds', 'Tonnage', and 'Tower 2' clearly demonstrated the occurrence of successful fertilization of self-pollinated flowers. The number of fruits per experimental branch and the normalized values of fruits per terminal of those fruits produced in bags protected from crosspollination were typical of those on adjacent open-pollinated branches. Although 'Simmonds' fruit set was greater in openpollinated branches, the amount of fruit set resulting from selfing was still comparable to the other cultivars. Although the number of remaining fruit were noted at maturity, so few fruit remained on either enclosed or open branches that statistical analysis of the results were meaningless. In many trees, no fruit remained on tagged branches, even on the open-pollinated branches. This situation is common in Florida. Most fruit production occurs in the upper portions of trees of most cultivars (Davenport, 1982). It is, thus, not unusual to lose all of the initially set fruit in portions of the lower canopy.

Although the avocado has evolved a mechanism to promote outcrossing and can be close-pollinated, the results here show that the West Indian cultivars in Florida also utilize self-pollination. The flower, thus, has the opportunity to be pollinated by complementary cultivars during Stage I, and there are indications that pollen sources during this opening may be located at great distances (Ellstrand, 1992). If, however, flowers are not pollinated during Stage I, then there is a second opportunity for self-pollination in the flowers that retain receptivity. Coupled with the previous study (Davenport, 1989), these results present 3 consecutive years of observation, which demonstrate that pollen deposition of Florida-grown cultivars occurs primarily during the second floral opening. This opening had been considered strictly male in function (Davenport, 1986). The results presented here prove that a substantial proportion of flowers in these cultivars retain female function during this second floral opening. The number of white stigmas present at the end of Stage II correlated with the number of flowers pollinated in each cultivar. Pollen transfer agents could be flower thrips, wind, or gravity. This phenomenon likely occurs in most commercial cultivars grown in Florida (Davenport, 1989). Moreover, reports of pollination in small mesh nets by Schroeder (1954) and normal pollen tube growth in pistils of similarly enclosed flowers by Vithanage (1990) suggests that this scheme may also be widespread in other avocado-growing areas when conditions are favorable for retention of a significant portion of receptive stigmas through Stage II. Self-pollination in Stage II has been observed in Israel, a dry Mediterranean climate, but pollen tubes were reported not to grow in those conditions (Davenport and Lahav, 1992). Recognizing that the availability of complementary cultivars should increase yield in climates that are conducive to stigma desiccation, productivity in large, solid blocks of a particular cultivar where flowering overlap does not frequently occur may be explained by the mechanism described here.

\section{Literature Cited}

Bergh, B.O. 1967. Reasons for low yields of avocados. California Avocado Soc. Yrbk. 51:161-172.

Bergh, B.O. and C.D. Gustafson. 1958. Fuerte fruit set as influenced by cross-pollination. California Avocado Soc. Yrbk. 42:64-66.

Clark, O.I. and A. Clark. 1926. Results of pollination and other experiments on avocados at the orchards of the Point Loma Homestead. California Avocado Assn. Yrbk. 10:85-94.

Davenport, T.L. 1982. Avocado growth and development. Proc. Florida State Hort. Soc. 95:92-96.

Davenport, T.L. 1986. Avocado flowering. Hort. Rev. 8:257-289.

Davenport, T.L. 1989. Pollen deposition on avocado stigmas in southern Florida. HortScience 24:844-845.

Davenport, T.L. 1992. Pollination habit of avocado cultivars in south Florida, p. 169-172. In: C.J. Lovatt (ed.). Proc. 2nd World Avocado Congr., Orange, Calif.

Davenport, T.L. and E. Lahav. 1992. Is a pollinator required to maximize avocado production? p. 667-668. In: C.J. Lovatt (ed.). Proc. 2nd World Avocado Congr., Orange, Calif.

Degani, C. and A. Goldring. 1989. Pollen parent effect on outcrossing rate in 'Hass' and 'Fuerte' avocado plots during fruit development. J. Amer. Soc. Hort. Sci. 114:106-111.

Degani, C., A. Goldring, S. Gazit, and U. Lavi. 1986. Genetic selection during the abscission of avocado fruitlets. HortScience 21:1187-1188. Ellstrand, N. 1992. Sex and the single variety. Calif. Grower 1:22-23.

Finazzo, S.F., T.L. Davenport, and B. Schaffer. 1994. Partitioning of photoassimilates in avocado (Persea americana Mill.) during flowering and fruit set. Tree Physiology 14:153-164. 
Fisher, J.B. and T.L. Davenport. 1989. Structure and devel deformations on avocado fruits. HortScience 24:841-84

$\mathrm{p}$ 